\title{
Quality of Life: Psychosocial environment factors in the event of disasters to private construction firms
}

\author{
Roshana Takim, Iffah Farhana Abu Talib, Abdul Hadi Nawawi \\ Faculty of Architecture, Planning \& Surveying, \\ University Teknologi MARA (UiTM), Shah Alam, Malaysia \\ dr_roshana@salam.uitm.edu.my
}

\begin{abstract}
In the last decade, both natural and man-made disaster events in Malaysia bring hindrance to construction firms' operations. Disaster events causing stress, anxiety and depression among people which leads to lose of working days. This research reports on psychosocial environment factors to private construction firms in the event of disaster. A semi-structured interviews were conducted among six (6) construction firms and the data were analysed using content analysis. The findings revealed that three (3) psychosocial environment factors (i.e., job characteristics; role in organisations; and social aspects) affected by man-made disasters; while job prospect and organisational factors distressed by natural disasters.

Keywords: Man-made Disaster; Natural Disaster; Private Construction Firms; Psychosocial Environment Factors

eISSN 2398-4279 @ 2018. The Authors. Published for AMER ABRA cE-Bs by e-International Publishing House, Ltd., UK. This is an open access article under the CC BY-NC-ND license (http://creativecommons.org/licenses/bync-nd/4.0/). Peer-review under responsibility of AMER (Association of Malaysian Environment-Behaviour Researchers), ABRA (Association of Behavioural Researchers on Asians) and $c E-B s$ (Centre for EnvironmentBehaviour Studies), Faculty of Architecture, Planning \& Surveying, Universiti Teknologi MARA, Malaysia.

https://doi.org/10.21834/ajqol.v3i11.130
\end{abstract}




\subsection{Introduction}

The construction industry has identified as one of the most hazardous industries in many parts of the world. The nature of the construction work is physically demanding which influence the quality of life on employees mortality, workers' compensation, injuries and fatalities (Chong \& Low, 2014). However, the frequency of disaster events across the globe over the years had led to the increase of psychosocial environment risks (i.e., job characteristic; role in organisations; social aspects; job prospects and organisational factors) among the construction employees. Apparently, the construction industry has become more stressful in dealing the nature of the trade and disaster events (Boschman et al., 2013). Hence, it is crucial to consider the psychosocial environment factors when dealing with construction firms and their workers (Alavinia et al., 2009). On the occurrences of disaster events, many parties such as company management; interest groups like investors, suppliers or clients could be affected (Low, Liu, \& Sio, 2010). Disaster events can be categorized into two, man-made and natural disasters. Man-made disasters events are such as equipment or system failure; human error (sabotage, terrorist); IT failure and security breach; utilities, property and services failures; external error (outsource issue, fraud, syndicate, public transportation disruption, workplace violence). Additionally, events of natural disasters are the earthquake; mass movement (landslide, land sinking); storm (lightning, thunderstorm); hydrological (river flood, flash flood, coastal flood); wildfire (forest, land fire); and extreme temperature (heat wave, drought) (MAMPU, 2014).

Concerning the above, European Statistics reported that subsequent to disaster events, 14,000 cases were filed on stress, anxiety and depression among people in construction firms which leads to 340,000 working days lost in construction trades (Boschman et al., 2013). This data supports the exploration of psychosocial environment issues that affect the construction firms and their workers.

\subsection{Quality of Life of Private Construction Firms in Events of Disaster}

Both man-made and natural disaster events cause significant damage and loss of lives, properties and organisations (Abdul-Rahman, 2014; Stringfellow, 2014). Over the past decade, about 532,851 Malaysians were affected (EM-DAT, 2015). Kuala Lumpur flash floods 2013, East-coast Malaysia river floods 2013, thick haze 2015 are some of the disasters that affected the operational of construction firms in Malaysia. Parts of the area covered by these disasters affected to some private construction firms underwent construction activities which eventually effects the quality of life. Quality of life measurement is to measure the extent to which people's 'happiness requirements' are met (McCall, 1975). Another definition of Quality of life is the degree to which a person enjoys the important possibilities of his/her life. Three major life domains are: Being, Belonging, and Becoming. In the construction field, quality of life is defined on how well workers can perform their jobs at present and in the near future, - the individuals' capacity and the work demands (Hengel et al., 2010).

Embedding a culture of quality of life is to tackle pressures on the environment and resources in any societies in the event of disasters. This is to strengthen resilience against disaster events, at the same time without severe losses and damages on social, economic 
and environmental aspects in construction industry. However, in Malaysia, the application of the right framework/model associated to employee-related quality of life in private construction firms are still lacking (Hays, 2015). As such, this could create acute disruption to their firms' construction activities and operations when disaster struck (EU-OSHA, 2015). Mismanage and lack of supervision in private construction firms in the event of disasters could downgrade the quality of life of their employees due to miscommunication and depression (Boschman et al., 2013). Furthermore, according to Wen et al., (2012), postdisaster events increase the physical diseases and symptom of post-traumatic stress disorder among individuals and these consequences causing the adverse quality of life. As such, prior establishing a strategy of quality of life in private construction firms, it is imperative to understand the culture of the firms to prevent abusive disaster management plan.

As for private construction firms, embedding quality of life prior disaster events, bring means the firms' culture and practices for long-term care, to sustain business growth and operation efficacy. Understanding the culture before establishing the quality of life strategies into the construction firms is important to prevent abusive disaster management plan. Therapeutic Psychosocial Environment Framework (TPEF) by Bell (2015) defines five elements (i.e., psychosocial environment; physical environment \& staffing; allocation of funding; policies \& procedures; and organisational philosophy) for the quality of life of private construction's firms. Meanwhile, a study conducted by Werezak \& Morgan (2003), further identified psychosocial environment could be divided into five (5) factors. These are job characteristic; role in the organisation; social aspects; job prospects; and organisational factors. The combination of both ideas is presented in Figure 1.

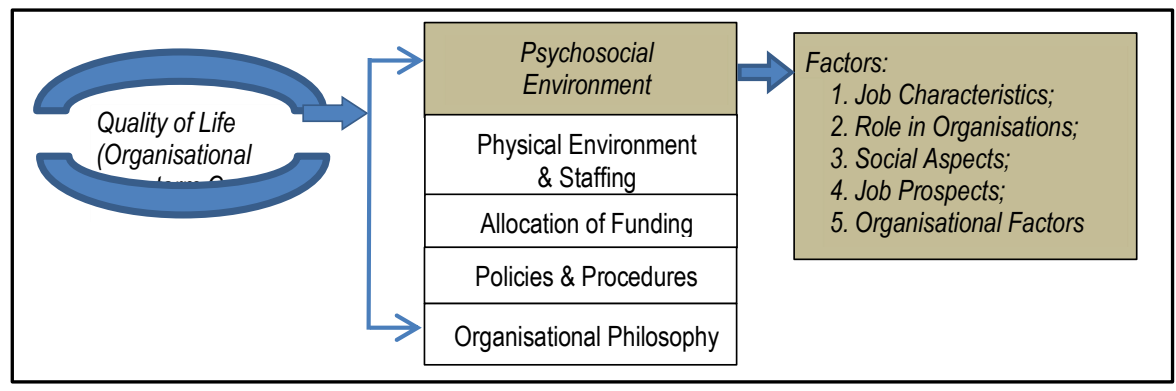

Figure 1. Therapeutic Psychosocial Environment Framework (Bell, 2015; Werezak \& Morgan, 2003).

Hence, the objective of this paper is to investigate psychosocial environment factors in the event of disasters to private construction firms. The purpose is to explore the effect of quality of life (in long term care) among employees in construction firms and their workers during disaster occurrences.

\section{Psychosocial Environment Factors}

The psychosocial environment is a niche of organisational long-term care that promotes 
quality of life. It refers to the culture, general practices and climate of the workplace. Table 1 presents psychosocial environment factors after disaster events in private construction firms from various scholars. The first factor of psychosocial environment for construction firm is job characteristics. Attributes such as work environment; workload and work pressure; weather conditions and long hour work requirement are the contributor risk for work-related depression and stress among the employees (Boschman et.al, 2013; Jia et.al, 2016; Nieuwenhuijsen et.al, 2010; Stattin \& Järvholm, 2005). Secondly, as for role in organisation factor, it includes job descriptions, responsibilities and skill utilisations. Additionally, Low et.al (2010) mention that age and experience also play the important role as these help the employees to prioritise actions after the disaster took place. However, conflicts on roles often happen in construction firms due to lack of work control, skill-underutilization and overcompensating on the job (Abbe et.al, 2011; Razzaghian \& Shah, 2011). Hence, employees must understand and comprehend their respective roles, during disaster events to establish healthy relationships and acceptable construction activities (Manyena, 2009; Stattin \& Järvholm, 2005).

Table 1. Psychosocial Environment Factors in Private Construction Firms

\begin{tabular}{|l|l|l|l|l|l|l|l|l|l|c|}
\hline $\begin{array}{l}\text { Psychosocial } \\
\text { Environment } \\
\text { Factors }\end{array}$ & $\begin{array}{l}\text { Lynch et } \\
\text { al. } \\
\text { (2000) }\end{array}$ & $\begin{array}{l}\text { Stattin \& } \\
\text { Järv- } \\
\text { holm, } \\
(2005)\end{array}$ & $\begin{array}{l}\text { Moe \& } \\
\text { Pathra- } \\
\text { narakul } \\
(2006)\end{array}$ & $\begin{array}{l}\text { Man- } \\
\text { yena } \\
(2009)\end{array}$ & $\begin{array}{l}\text { Low, } \\
\text { Liu, \& } \\
\text { Sio } \\
(2010)\end{array}$ & $\begin{array}{l}\text { Nieuwen- } \\
\text { huijsen, } \\
\text { Bruinvels, } \\
\text { \& Frings- } \\
\text { Dresen } \\
(2010)\end{array}$ & $\begin{array}{l}\text { lbbe, } \\
\text { et.al } \\
(2011)\end{array}$ & $\begin{array}{l}\text { Bosch- } \\
\text { man } \\
\text { et. al } \\
(2013)\end{array}$ & $\begin{array}{l}\text { Bell } \\
(2015)\end{array}$ & $\begin{array}{l}\text { Jia, et.al } \\
(2016)\end{array}$ \\
\hline Job Characteristic & & $\checkmark$ & $\checkmark$ & $\checkmark$ & $\checkmark$ & $\checkmark$ & $\checkmark$ & $\checkmark$ & $\checkmark$ & $\checkmark$ \\
\hline $\begin{array}{l}\text { Role in } \\
\text { Organisations }\end{array}$ & & $\checkmark$ & & $\checkmark$ & $\checkmark$ & & & $\checkmark$ & $\checkmark$ & $\checkmark$ \\
\hline Social Aspects & $\checkmark$ & $\checkmark$ & $\checkmark$ & & & $\checkmark$ & & $\checkmark$ & $\checkmark$ & $\checkmark$ \\
\hline Job Prospects & $\checkmark$ & $\checkmark$ & & & & $\checkmark$ & & $\checkmark$ & $\checkmark$ & \\
\hline $\begin{array}{l}\text { Organisational } \\
\text { Factors }\end{array}$ & & $\checkmark$ & $\checkmark$ & & $\checkmark$ & $\checkmark$ & $\checkmark$ & $\checkmark$ & $\checkmark$ & $\checkmark$ \\
\hline
\end{tabular}

Meanwhile, social aspects in construction firms are one of the psychosocial factors that contribute to their social climate and culture. Damage level of disaster events towards the construction firms' employees could cause a post-traumatic stress disorder; interpersonal conflicts and emotional demands (Nieuwenhuijsen et al., 2010; Razzaghian \& Shah, 2011). Furthermore, Boschman et al., 2013 claimed that low social support given to employees create most adverse effects to the construction firms. This condition will eventually affect the quality of life within the construction firms in the long term.

In regards to the effects of disaster events to construction firms, job prospects factor among construction employees covers job development; salaries; job insecurity and precarious work contract (Bell, 2015; EU-OSHA, 2015). However, these factors could be a constant stressor for employees with improper management by their construction firms in the event of disasters (Boschman et al., 2013; Nieuwenhuijsen et al., 2010). Additionally, Lynch et al. (2000) found out that inequality salaries and discrimination treatment; and uncertainty on work contracts affect the atmosphere of construction firms. 
Lastly, organisational factors could influence private construction firms which includes leadership culture (i.e., information and consultation on work nature); management plan and style; and the firms' procedure and policies on events of disasters (Bell, 2015; EU-OSHA, 2015; Moe \& Pathranarakul, 2006). Nonetheless, these factors potentially manoeuvre the mental and physical wellbeing of the construction firms' employees. Challenges arise when management team and the employees have to perform their work under pressure in covering up the lost time and cost, caused by disaster occurrences.

Given the above, most of the psychosocial environment factors mentioned are contributing to private construction firms' culture to cope and protect their business and sustainability from a severe effect on quality of life in the event of disaster. Among others literature revealed that 'job characteristics'; 'organisational factors' and 'social aspects' are the prominent issues that has been highlighted by most scholars.

\subsection{Methodology}

\subsection{Literature Review}

Literature review were conducted on Psychosocial Environment Factors (PEF); types of manmade and natural disasters; and effect of psychosocial environment factors to quality of life. The concepts and scientific explanations for these keywords will be identified to answer the question on 'how psychosocial environment factors influence the construction firms; and why these factors could affect the employee-related quality of life'.

\subsection{Preliminary Data Collection}

For the preliminary data collection, a face-to-face semi-structured interviews have been conducted to six respondents from private construction organisations in Malaysia that involved in both natural and man-made disaster events. Two sets of data are required on (1) psychosocial environment factors (PEF) and (2) effect of PEF to quality of life among employees in construction firms during disaster occurrences. Purposive sampling was used across these semi-structured interviews. According to Palys (2008), purposive sampling are selected as the respondents fulfil certain attribute required for the research aim. Thus, in this paper, selecting purposive sampling mentioned above would provide particular information to achieve the research objective, which is to explore the effect of psychosocial factors in private construction firms to sustain growth in the event of disasters (man-made and natural).

\subsection{Limitation}

The limitations of this study are: data are solely collected from private construction firms that had been involved in the event of disaster (man-made and natural). Those are not involved are eliminated. The second limitation is that for the purpose of this paper, data on employeerelated quality of life is not included. Hence, comprehensive data on employee-related quality of life will be conducted and will be reported in the next conference.

Table 2 showed the sample of respondent involved in the interview. Based on the designation, it is rational to deduce that the respondents have reasonable knowledge and 
experience concerning to disaster events within their firms. The respondents' experience in the construction industry is between 6-30 years with an overall average of approximately 16.17 years; which gives a reliable extent of experience in the sample (Takim, 2005). The interviews were recorded and transcribed verbatim for content analysis, with each interview lasted for 30 to 45 minutes.

Table 2. Sample of Interview Respondents from Private Construction Firms

\begin{tabular}{|c|l|c|l|}
\hline $\begin{array}{l}\text { Respondents } \\
\text { from Private } \\
\begin{array}{l}\text { Construction } \\
\text { Firms }\end{array}\end{array}$ & Designation & $\begin{array}{l}\text { Experience in } \\
\text { Construction } \\
\text { Industry } \\
\text { (years) }\end{array}$ & Experience on Disaster Events \\
\hline R1 & Planning Manager & 12 & Haze, river flood and power failure \\
\hline R2 & Senior Land Surveyor & 19 & Haze, theft (raw materials) \\
\hline R3 & Project Manager & 7 & $\begin{array}{l}\text { Haze, flash flood, material loss (cement and } \\
\text { electrical cable) }\end{array}$ \\
\hline R4 & Planning Engineer & 6 & Flash flood, electrical utilities theft syndicate \\
\hline R5 & Senior Land Surveyor & 30 & $\begin{array}{l}\text { Fire outbreak, structure collapsed (fatality), } \\
\text { mosquito infestation }\end{array}$ \\
\hline R6 & $\begin{array}{l}\text { Senior Project } \\
\text { Engineer }\end{array}$ & 23 & $\begin{array}{l}\text { Landslide, scaffolding collapsed (fatality), } \\
\text { tower crane collapsed (fatality), basement flood }\end{array}$ \\
\hline
\end{tabular}

\subsection{Findings and Discussions}

\section{Psychosocial Environment Factors of Private Construction Firms in Malaysia}

Table 3 showed lists of psychosocial environment factors practised in respondents' construction firms. From the interviews, it can be deduced that factors on job characteristic (83\%); role in organisations (50\%) and social aspects (83\%) were more affected by manmade disaster events compared to the natural disaster for private construction firms.

According to Yasuyuki, Bhattcharyay \& Kotera (2011), man-made disaster events caused severe adverse effects such as financial crises and economic costs to the private construction firms compared to natural disasters. Respondent R1, R2, R3, R4 and R5 agreed that man-made disaster events such as power failure, material losses, theft, and the structure collapsed were affecting their job characteristics. The probable reason for this exertion is that as mentioned by Respondent 1 (R4), "Our companies had difficulties to replace back the stolen materials due to workers syndicate, they sell the materials to the third party. Everyone in the team has to be alert at all times on the construction site".

On the other hand, R2, R3 and R4 mentioned that their role in organisations in respective firms was not clearly stated on actions to be taken when disaster occurred which made them act without any guidelines. Meanwhile, the social aspects factors were affected by man-made disaster events as opinionated by R2, R3, R4, R5 and R6. This also mentioned by Bell (2015) that high emotional and welfare demand among the employees creates negative atmosphere at the workplace. These uncertainty factors were affected by man-made disaster events to private construction firms in Malaysia.

The results on job prospect and organisational factors, on the other hand, revealed that 
natural disasters affected the private construction firms' quality of life. R1, R2, R4 and R5 reported that, job prospect factor was intimated by natural disaster events. Their past experiences dealt with flash flood and haze had caused the psychological effect on job uncertainty and shady work contract which eventually gave negative impact on employees' health and wellbeing (Boschman et al., 2013; Razzaghian \& Shah, 2011).

Table 3. Psychosocial Environment Factors practiced in respondents' construction firms

\begin{tabular}{|c|c|c|c|c|c|c|c|c|c|}
\hline $\begin{array}{l}\text { Psychosocial } \\
\text { Environment } \\
\text { Factors }\end{array}$ & $\begin{array}{l}\text { Literature } \\
\text { Review }\end{array}$ & $\begin{array}{l}\text { Types of } \\
\text { Disaster }\end{array}$ & R1 & R2 & R3 & R4 & R5 & R6 & Frequency \\
\hline \multirow[b]{2}{*}{ Job Characteristic } & \multirow[b]{2}{*}{$90 \%$} & Man-made & $\checkmark$ & $\checkmark$ & $\checkmark$ & $\checkmark$ & $\checkmark$ & & 5 \\
\hline & & Natural & $\checkmark$ & $\checkmark$ & $\checkmark$ & $\checkmark$ & & & 4 \\
\hline \multirow[b]{2}{*}{$\begin{array}{l}\text { Role in } \\
\text { Organisations }\end{array}$} & \multirow[b]{2}{*}{$60 \%$} & Man-made & & $\checkmark$ & $\checkmark$ & $\checkmark$ & & & 3 \\
\hline & & Natural & & $\checkmark$ & & $\checkmark$ & & & 2 \\
\hline \multirow[b]{2}{*}{ Social Aspects } & \multirow[b]{2}{*}{$70 \%$} & Man-made & & $\checkmark$ & $\checkmark$ & $\checkmark$ & $\checkmark$ & $\checkmark$ & 5 \\
\hline & & Natural & & $\checkmark$ & $\checkmark$ & $\checkmark$ & & & 3 \\
\hline \multirow[b]{2}{*}{ Job Prospects } & \multirow[b]{2}{*}{$50 \%$} & Man-made & & $\checkmark$ & & $\checkmark$ & & & 2 \\
\hline & & Natural & $\checkmark$ & $\checkmark$ & & $\checkmark$ & $\checkmark$ & & 4 \\
\hline \multirow{2}{*}{$\begin{array}{l}\text { Organisational } \\
\text { Factors }\end{array}$} & \multirow[b]{2}{*}{$80 \%$} & Man-made & & $\checkmark$ & $\checkmark$ & $\checkmark$ & & & 3 \\
\hline & & Natural & $\checkmark$ & $\checkmark$ & $\checkmark$ & $\checkmark$ & $\checkmark$ & & 5 \\
\hline
\end{tabular}

Likewise, natural disaster events had shaken up the organisational factors for the private construction firms. R1, R2, R3, R4 and R5 explained that from their experiences with flood events, had affected the firms' communication and instructions between management team and workers to overcome issues raised from disaster events. This was proven by research studied by Jia et al. (2016) and Nieuwenhuijsen et al. (2010) where there would appear inconvenience on organisational factors such as leadership culture; management style; procedure and policies in private construction firms in the event of natural disasters. According to Respondent 3 (R3), "Our company did not specifically have procedures or policies to face the disasters. As such, we have to make our own decision with hesitation whether it will work effectively or otherwise."

\subsection{Conclusion}

This paper has presented the findings on the effect of psychosocial environment factors to private construction firms' in the event of disaster in Malaysia. This is to sustain the firms' business continuity and operation efficacy in long term. From the findings above, it can be derived that man-made disaster events affect job characteristics, role in organisations and social aspects to private construction firms; while natural disaster events affect the job prospects and organisational factors. 
Over the past decades, the frequency and magnitude of man-made disasters across the globe create greater risks and impacts to the community especially to the dynamic group in construction industry. Man-made disaster such as theft, material loss syndicate, and scaffolding collapsed caused major impact to the construction firms compared to natural disasters. Thus, these events affected the human behaviour, health and wellbeing among the employees of the private construction firms. Additionally, man-made disaster events disrupts job characteristics which includes productivity work pressure (i.e., shorter production times to cover the loss times) and higher work demand (work more and long hours). This ultimately influence the psychosocial environment for the employees. Other than that, the employees' role in organisations are highly affected by man-made disaster event. Without having unclear instructions to be taken pertaining to disaster events create conflicting work demands within the private construction firms' climate. Moreover, man-made disaster pretentious to social aspects factors where one of major difficulties among the employees is to establish work-life balance. Congruently, without proper disaster management plan or disaster mitigation plan, the disruption of disaster to the private construction firms' activities and operations could lead to further economic and financial crises.

Meanwhile, not to forget the natural disaster events such as flood (flash flood, river flood, and basement flood), haze (poor air quality, extreme heat and drought) occurred in Malaysia induced the psychosocial environment factors of job prospects and organisational factors. The impact from natural disasters could be calamitous, fatality cases and property damages. Natural disaster events created distress on job prospects factor among private construction firms' management team and workers which includes job insecurity; uncertainty on work contracts; discrimination on salary payments and career development. In addition, natural disaster events also influence the organisational factors. Weak management styles, loopholes on procedures and policies of the private construction firms could create stress among the employees and decrease their quality of life. However, the effect to the private construction firms are not as great as man-made disaster events. The data also reported that natural disaster events somehow affect the private construction firms as a whole but give less impact to the individuals in the firms.

From the above mentioned, it is vivid to establish a proper disaster management plan like business continuity and disaster recovery plan in the private construction firms in Malaysia. This is to ensure that business continuity plan culture embedded in the construction firms by raising awareness to the management team. Prior to that, the private construction companies shall understand their respective firms to determine the best disaster management plan to establish. Then, the private construction firms shall develop and implement the disaster management plan accordingly. In relation to quality of life of the construction firms and their workers, implementation of the disaster management plan could reduce critical operations during major interruptions caused by disaster events.

For future research, an extensive data collection (a bigger sampling) is planned to be carried out to more respective private construction firms that involved in both man-made and natural disasters. The data could be retrieved from various companies registered with Malaysian Construction Industry Development Board that has involved in disaster events. It is hoped that a bigger sample could reveal realistic results on the psychosocial environment 
that affect the quality of life of private construction firms in the event of disasters. In addition, comprehensive data on employee-related quality of life will be conducted and will be reported in the next conference.

This research presented in the paper is part of ongoing Ph.D. research to develop a framework of Business Continuity and Disaster Recovery Management (BCDRM) for private construction firms in Malaysia. The results of the study could provide an insight to Malaysian construction firms pertaining to disaster events.

\section{Acknowledgement}

The author would like to acknowledge the contribution from Research Management Institute (RMI) of Universiti Teknologi MARA (UiTM) and Ministry of Higher Education (MOHE) through supporting the research with Research Entity Initiative (REI) - Disaster Mitigation and Prevention Research Group: 600-RMI/DANA 5/3/REl (9/2015).

\section{References}

Abbe, O. O., Harvey, C. M., Ikuma, L. H., \& Aghazadeh, F. (2011). Modeling the Relationship Between Occupational Stressors, Psychosocial/Physical Symptoms and Injuries in the Construction Industry. International Journal of Industrial Ergonomics, 41(2), 106-117.

Alavinia, S. M., Van Den Berg, T. I. J., Van Duivenbooden, C., Elders, L. A., \& Burdorf, A. (2009). Impact of Workrelated Factors, Lifestyle, and Work Ability on Sickness Absence Among Dutch Construction Workers. Scandinavian Journal of Work, Environment and Health, 35(5), 325-333.

Bell, N. (2015). Psychosocial issues in construction. EU-OSHA, Campaign 2.

Boschman, J. S., van der Molen, H. F., Sluiter, J. K., \& Frings-Dresen, M. H. W. (2013). Psychosocial Work Environment and Mental Health Among Construction Workers. Applied Ergonomics, 44(5), 748-755. http://doi.org/10.1016/j.apergo.2013.01.004.

Chong, H. Y., \& Low, T. S. (2014). Accidents in Malaysian Construction Industry : Statistical Data and Court Cases, 3548(March), 37-41. http://doi.org/10.1080/10803548.2014.11077064.

EU-OSHA. (2015). Psychosocial Risks and Stress at Work. European Agency for Safety and Health at Work. Retrieved from https://osha.europa.eu/en/topics/stress/index_html.

Jia, Y. A., Rowlinson, S., \& Ciccarelli, M. (2016). Climatic and Psychosocial Risks of Heat Illness Incidents on Construction Site. Applied Ergonomics, 53, 25-35. http://doi.org/10.1016/j.apergo.2015.08.008.

Low, S. P., Liu, J., \& Sio, S. (2010). Business Continuity Management in Large Construction Companies in Singapore. Disaster Prevention and Management, 19(2), 219-232. http://doi.org/10.1108/09653561011038011.

Lynch, J. W., Smith, G. D., Kaplan, G. a, \& House, J. S. (2000). Income Inequality and Mortality: Importance to Health of Individual Income, Psychosocial Environment, or Material Conditions. BMJ (Clinical Research Ed.), 320(7243), 1200-1204. 
MAMPU. (2014). Disaster And Business Continuity Management. Malaysian Administrative Modernisation and Management Planning Unit.

Manyena, S. B. (2009). Disaster Resilience in Development and Humanitarian Interventions. University of Northumbria, Newcastle.

McCall, S. (1975). Quality of Life. Social Indicators Research, 2, 229-248. http://doi.org/10.1007/BF00300538.

Moe, T. L., \& Pathranarakul, P. (2006). An integrated approach to natural disaster management: Public project management and its critical success factors. Disaster Prevention and Management, 15(3), 396-413. http://doi.org/10.1108/09653560610669882.

Nieuwenhuijsen, K., Bruinvels, D., \& Frings-Dresen, M. (2010). Psychosocial Work Environment and Stress-Related Disorders, A Systematic Review. Occupational Medicine, 60(4), 277-286. http://doi.org/10.1093/occmed/kqq081.

Palys, T. (2008). Purposive Sampling. In The Sage Encyclopedia of Qualitative Research Methods (Vol. 2, pp. 6978). Los Angeles.

Razzaghian, M., \& Shah, A. (2011). Prevalence, antecedents, and Effects of Workplace Bullying: A review. African Journal of Business Management, 5(35), 13419-13427. http://doi.org/10.5897/AJBMX11.021

Stattin, M., \& Järvholm, B. (2005). Occupation, work environment, and disability pension: a prospective study of construction workers. Scandinavian Journal of Public Health, 33(August 2004), 84-90. http://doi.org/10.1080/14034940410019208

Takim, R. (2005). Process Improvement of Construction Projects in Malaysia: Analysis of Case Studies. Proceedings of the 2nd Scottish Conference for Postgraduate Researchers of Built and Natural Environment (PRoBE), 263-273.

Werezak, L., \& Morgan, D. (2003). Creating a Therapeutic Psychosocial Environment in Dementia Care: A Preliminary Framework. Journal of Gerontological Nursing, 29(12), 18-25.

Yasuyuki, S., Bhattcharyay, R., \& Kotera, T. (2011). Aggregate Impacts of Natural and Man-made Disasters : A Quantitative Comparison. 